Vol. 3, No 1, Juni 2020

Hal 54-66

\title{
EVALUASI DAN TINGKAT PARTISIPASI MASYARAKAT DALAM PENGELOLAAN KAWASAN KONSERVASI MANGROVE DI DESA MUNTE KECAMATAN TANALILI KABUPATEN LUWU UTARA
}

\author{
(Evaluation and Level of Community Participation in The Management of \\ Mangrove Conservation Areas in Munte Village, Tanalili District, \\ North Luwu Regency) \\ Amnaeni'), Asbar ${ }^{2)}$, dan Danial ${ }^{2)}$ \\ 1) Dinas Perikanan Kabupaten Luwu Utara \\ 2) Program Studi Manajemen Pesisir dan Teknologi Kelautan, PPS UMI Makassar
}

Korespondensi:amnaeniamin@gmail.com

Diterima: tanggal 1 Februari 2020; Disetujui 15 Maret 2020

\begin{abstract}
ABSTRAK
Evaluasi dan tingkat partisipasi masyarakat dalam pengelolaan kawasan konservasi mangrove di Desa Munte Kecamatan Tanalili Kabupaten Luwu Utara. Penelitian ini bertujuan untuk : 1) Mengevaluasi tingkat partisipasi masyarakat dalam pengelolaan ekosistem mangrove; 2) Menentukan arahan strategi pengelolaan ekosistem mangrove. kegunaan penelitian diharapkan dapat memberikan informasi kepada stakeholder sebagai bahan pertimbangan dalam mengambil kebijakan pengelolaan ekosistem mangrove. Metode yang digunakan dalam penelitian ini yaitu menggunakan kuesioner. Data mengenai faktor internal yaitu karakteristikin dividu peserta dalam pengelolaan mangrove di kawasan wisata mangrove yang dilakukan dengan mengisi kuesioner dan wawancara. Hasil Partisipasi masyarakat terhadap kriteria $75 \%$ memiliki tingkat partisipasi yang tinggi dengan menunjukkan bahwa nilai rata- rata skala linkert menunjukkan rentang positif. Sementara $25 \%$ kriteria menunjukkan tingkat partisipasi yang rendah dengan nilai rentang negative, dengan kata lain sebagian masyarakat menganggap bahwa mangrove tidak memiliki manfaat penting bagi tambak. Strategi pengelolan berdasarkan skala yang dihasilkan untuk pengelolaan ekosistem mangrove di DesaMunte, yaitu (1) Menyelenggarakan pelatihan-pelatihan keterampilan pengelolaan mangrove ( ekowisata dan kebun bibit ) untuk meningkatkan pendapatan masyarakat serta (2) Membuat regulasi untuk mengontrol pemanfaatan mangrove berbasis masyarakat dan juga pelanggaran-pelanggaran pengelolaan mangrove.
\end{abstract}

Kata kunci: Evaluasi, partisipati, mangrove, pengelolaan, Luwu Utara

\section{ABSTRACT}

Evaluation and level of community participation in the management of mangrove conservation areas in Munte Village, Tanalili District, North Luwu Regency. This study aimed to: 1) Evaluate the level of community participation in the management of mangrove; 2) Determine the direction of the mangrove ecosystem management strategy. In addition, it was expected to provide information to stakeholders as a material consideration in taking mangrove ecosystem management policies in Munte Village, Tanalili District, North Luwu Regency. The research method was done by using a questionnaire. The data on internal factors namely the characteristics of participants' dividends in the management of mangroves of the mangrove tourism area which was done by filling out questionnaires and interviews. The results Community participation in the $75 \%$ criterion had a high level of participation by showing that the average value of the linkert scale showed a positive range. $25 \%$ of criteria indicated a low level of participation with a negative range value, some people consider that mangroves had unimportant benefits for the farm. The management strategy based on the scale produced for the management of mangrove ecosystems in Munte, namely (1) Organizing training on mangrove management skills (ecotourism and nursery) to increase community income and (2) Making regulations to control the use of community-based mangroves and also violations mangrove management violations.

Keywords: Evaluation, Participation, Mangrove, Management, North Luwu Regency. 
PENDAHULUAN

Pertambahan jumlah penduduk, pembuatan lahan tambak, dan pemanfaatkan kayu mangrove secara berlebihan di kawasan pesisir menyebabkan tekanan terhadap ekosistem mangrove. Menurut Rusila, Khazali dan Suryadiputra (1999) Indonesia merupakan negara yang mempunyai luas hutan mangrove terluas di dunia dengan keragaman hayati terbesar di dunia dan struktur paling bervariasi di dunia.

Datta et al. (2012) menjelaskan ekosistem mangrove Indonesia bahkan mangrove dunia dibayangi oleh berbagai ancaman kerusakan ekosistem yang semakin lama semakin tinggi baik secara alami maupun dengan adanya campur tangan manusia. Kerusakan mangrove diantaranya disebabkan oleh tekanan dan pertambahan penduduk yang demikian cepat terutama di daerah pesisir dan mengakibatkan adanya perubahan tata guna lahan dan pemanfaatan sumberdaya alam secara berlebihan, akibatnya ekosistem hutan mangrove dengan cepat menipis dan rusak. Oleh sebab itu, perlu diadakan pengelolaan untuk mengatur hubungan timbal balik antara sumberdaya alam dan manusia agar terwujud kelestarian serta menjamin ke berlanjutan manfaat sumberdaya alam tersebut bagi manusia.

Penelitian ini bertujuan untuk mengevaluasi tingkat partisipasi masyarakat dalam pengelolaan ekosistem mangrove dan menentukan arahan strategi pengelolaan ekosistem mangrove di Desa Munte Kecamatan Tanalili. Selain itu penelitian ini diharapkan dapat menambah pengetahuan dan wawasan mengenai partisipasi masyarakat dalam pengelolaan ekosistem mangrove.

\section{MATERI DAN METODE}

Penelitian ini dilaksanakan pada tanggal 5 September sampai tanggal 7 November 2019 di pesisir pantai desa Munte, Kecamatan Tanalili,kabupaten Luwu Utara. Jangka waktu tersebut meliputi studi literatur, analisis data, pengecekan lapangan, dan penulisan laporan akhir 


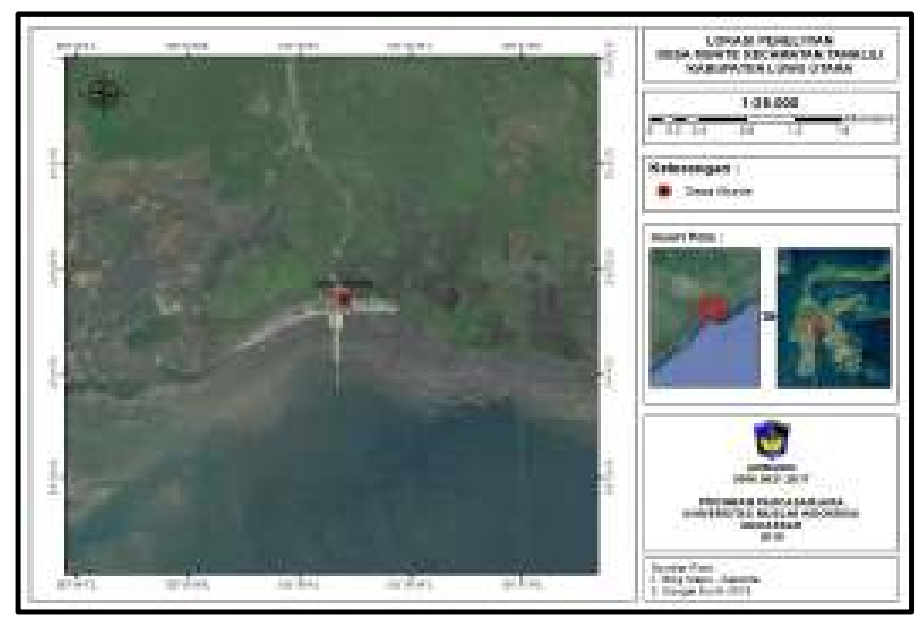

Gambar 1. Peta Lokasi Penelitian

Proses pengambilan data lapangan dan analisis data pada penelitian ini dibantu dengan menggunakan beberapa alat dan bahan. Adapun alat dan bahan beserta kegunaanya disajikan pada tabel:

Tabel 1. Alat dan Bahan Penelitian

\section{Alat dan Bahan}

a. Kamera

b. Alat Tulis

c. Kuisioner

d. Personal Computer (PC)

\section{Kegunaan}
Untuk dokumentasi
Untuk Mencatat
Untuk data Responden
Untuk mengolah data

Jenis data yang digunakan adalah di sekitar hutan mangrove di pesisir data primer dan sekunder. Data Desa Munte meliputi persepsi dan mengenai faktor internal yaitu partisipasi masyarakat dalam karakteristik individu peserta dalam pelestarian ekosistem mangrove yang pengelolaan mangrove di kawasan ada di wilayah pesisir desa Munte.

wisata mangrove yang dilakukan - Persepsi Masyarakat

dengan mengisi kuesioner dan Persepsi masyarakat yang dikaji wawancara.

dalam penelitian ini berkaitan dengan

Metode penelitian secara umum pemikiran dan pendapat masyarakat yang digunakan dalam penelitian ini tentang isu dan suatu tindakan yang adalah studi kasus (Case Study). berkaitan dengan upaya pelestarian dan Variable yang diteliti dalam penelitian pemanfaatan hutan mangrove yang ada sosial budaya masyarakat ini yang ada di wilayah pesisir desa Munte. 


\section{- Partisipasi Masyarakat}

Partisipasi dikaji dalam penelitian ini berkaitan dengan keikutsertaan masyarakat secara individu, kolektif maupun kelembagaan dalam upaya pengelolaan hutan mangrove yang ada di wilayah pesisir desa Munte.

\section{Analisis Data}

Analisis tingkat partisipasi, pada tanggal 05 juni 2012.

untuk menghadapi ancaman yang akan datang (WT).

\section{HASIL DAN PEMBAHASAN}

Tana

Lili adalah sebuah kecamatan di Kabupaten Luwu Utara, Sulawesi

Selatan, Indonesia yang sebelumnya merupakan kecamatan pemekaran dari Kecamatan Bone-Bone yg dimekarkan dilakukan dengan metode analisis Munte adalah desa di kecamatan TanaL deskripsi. Metode yang digunakan ili, Kabupaten Luwu Utara, Sulawesi untuk mengukur persepsi masyarakat Selatan, Indonesia. Responden pada adalah metode skala Likert dan indeks penelitian ini mayoritas bekerja sebagai persepsi masyarakat (IPm). nelayan. Menurut Pangestu (1995),

Arahan Strategi Pengelolaan, faktor internal adalah faktor yang dapat meliputi Alternatif strategi pada memengaruhi partisipasi individu matriks hasil analisis SWOT seperti dalam suatu kegiatan sosial. disajikan pada table dihasilkan dari: - Umur penggunaan unsur-unsur kekuatan kawasan untuk mendapatkan peluang dilalui seseorang.Usia produktif berada yang ada (SO), penggunaan kekuatan pada rentang umur 15-64 tahun (Rusli yang ada untuk menghadapi ancaman 2012). Pengkategorian tingkat umur yang akan datang (ST), pengurangan responden pada penelitian ini diukur kelemahan kawasan yang ada dengan dalam jumlah tahun berdasarkan memanfaatkan peluang yang ada (WO) sebaran rata-rata usia responden yang dan pengurangan kelemahan yang ada ditemui di lapang. 
Tabel 2. Jumlah dan persentase responden berdasarkan umur di Desa Munte tahun 2019

\begin{tabular}{ccc}
\hline Umur & \multicolumn{2}{c}{ Responden } \\
\cline { 2 - 3 } (Tahun) & $\mathrm{n}$ & $\%$ \\
\hline $18-22$ & 2 & 4 \\
$22-27$ & 6 & 12 \\
$27-32$ & 10 & 20 \\
$>32$ & 32 & 64 \\
\hline Jumlah & 50 & 100 \\
\hline
\end{tabular}

Sumber: Data olah primer, 2019

Pada tabel diatas menunjukkan melakukan kegiatan partisipatif lebih bahwa umur responden yang paling besar kemungkinan berhasilnya pada banyak diwawancarai dengan umur $>32$ usia produktif (Tambunan, Harahap, tahun yaitu sebesar $64 \%$, dan yang dan Lubis 2005).

terendah dengan kisaran umur 18 - 22 - Tingkat Pendidikan

tahun sebesar $4 \%$. Umur yang berada Tingkat pendidikan yang di usia produktif memberikan peluang dimaksud dalam penelitian ini adalah yang potensial bagi pengelolaan hutan jenjang pendidikan formal yang mangrove yang partisipatif. Hal ini ditempuh oleh responden.

didasari atas kemampuan menyerap dan

Tabel 3. Jumlah dan persentase responden berdasarkan tingkat pendidikan di Desa Munte tahun 2019

\begin{tabular}{crr}
\hline Tingkat & \multicolumn{3}{c}{ Responden } \\
\cline { 2 - 3 } Pendidikan & $\mathrm{n}$ & $\%$ \\
\hline SD & 9 & 18 \\
SMP & 17 & 34 \\
SMA/SMK & 14 & 28 \\
Lainnya & 10 & 20 \\
\hline Jumlah & 50 & 100 \\
\hline
\end{tabular}

Sumber: Data olah primer 2019

Pada tabel diatas menunjukkan pendidikan SD sebesar $18 \%$. Menurut bahwa tingkat pendidikan yang paling Tambunan, Harahap dan Lubis (2005), banyak saat wawancara yaitu SMP taraf pendidikan yang beragam akan sebesar $34 \%$, kemudian SMA/SMK memengaruhi daya nalar setiap sebesar $28 \%$, Lainnya (S1) sebesar 20 individu, sehingga ada kemungkinan $\%$, dan yang terendah dengan tingkat melakukan penafsiran yang berbeda 
terhadap program yang dilaksanakan dalam pengelolaan hutan mangrove.

\section{- Tingkat Pendapatan}

Tingkat pendapatan responden di lokasi penelitian dapat dilihat pada Tabel dibawah :

Tabel 4. Jumlah dan persentase responden berdasarkan pendapatan di Desa Munte tahun 2019

\begin{tabular}{crr}
\hline Pendapatan & \multicolumn{3}{c}{ Responden } \\
\cline { 2 - 4 } & n & \% \\
\hline$<1.000 .000$ & 4 & 8 \\
$1.000 .000-2.000 .000$ & 18 & 36 \\
$2.000 .000-3.000 .000$ & 15 & 30 \\
$>3.000 .000$ & 13 & 26 \\
\hline Jumlah & $\mathbf{5 0}$ & $\mathbf{1 0 0}$ \\
\hline
\end{tabular}

Sumber: Data olah primer 2019

Pada tabel diatas menunjukkan sumbangsih mengenai partisipasi dalam bahwa pendapatan responden yang rehabilitasi mangrove.Semakin tinggi paling banyak saat wawancara yaitu tingkat penghasilan semakin besar $1.000 .000-2.000 .000$ sebesar $36 \%$, kemungkinan partisipasi dalam kemudian yang terendah dengan rehabilitasi mangrove.

\section{$<1.000 .000$ sebesar $8 \%$. Berdasarkan - Lama Tinggal}

hasil penelitian Bahagia (2008), tingkat Berikut lama tinggal responden pendapatan berkaitan erat dengan disajikan pada tabel berikut ini :

Tabel 5. Jumlah dan persentase responden berdasarkan lama tinggal di Desa Munte tahun 2019

\begin{tabular}{ccr}
\hline Lama Tinggal (Tahun) & \multicolumn{3}{c}{ Responden } \\
\cline { 2 - 3 } & $\mathrm{n}$ & $\%$ \\
\hline 20 (Baru) & 11 & 22 \\
$20-40$ (Sedang) & 20 & 40 \\
$>40$ (Lama) & 19 & 38 \\
\hline Jumlah & 50 & 100 \\
\hline Sumber: Data olah primer 2019 & &
\end{tabular}

Berdasarkan pada tabel diatas, yang sudah tinggal di lokasi penelitian terdapat 11 responden yang baru selama 20 - 40 tahun, sedangkan tinggal $(<20$ tahun $)$ di lokasi responden yang tinggal lebih dari 40 penelitian atau sekitar $22 \%$. Selain tahun di lokasi penelitian ada 19 itu, ada 20 responden ataupun $40 \%$ orang/responden atau sekitar $38 \%$. 
Persepsi masyarakat pesisir terhadap (1999) bahwa masyarakat yang hutan mangrove dapat menjadi salah berdomisili lama atau sejak lahir satu indikator ataupun alat ukur untuk menetap di suatu wilayah telah melihat pengetahuan dan pemahaman turuntemurun menjalankan kehidupan mereka tentang ekosistem mangrove tradisional yang dicirikan dengan beserta fungsi-fungsinya baik secara eratnya hubungan mereka dengan ekologi, sosial maupun ekonomi. Hal alam sekitar.

ini diperkuat oleh pendapat Manulang

\begin{tabular}{|c|c|c|c|c|c|c|c|}
\hline No & Pernyataan & STS & $\mathrm{TS}$ & $\mathrm{N}$ & S & $\mathrm{SS}$ & Jumlah \\
\hline \multirow[t]{2}{*}{1} & $\begin{array}{l}\text { Kerusakan Wilayah } \\
\text { pesisir karena faktor } \\
\text { alam }\end{array}$ & 0 & 3 & 5 & 24 & 18 & 50 \\
\hline & $\%$ & 0 & 6 & 10 & 48 & 36 & 100 \\
\hline \multirow[t]{2}{*}{2} & $\begin{array}{l}\text { Kerusakan wilayah } \\
\text { pesisir lebih karena } \\
\text { perbuatan manusia }\end{array}$ & 1 & 3 & 2 & 36 & 8 & 50 \\
\hline & $\%$ & 2 & 6 & 4 & 72 & 16 & 100 \\
\hline \multirow[t]{2}{*}{3} & $\begin{array}{l}\text { Kerusakan hutan } \\
\text { mangrove karena } \\
\text { abrasi dan } \\
\text { kepentingan ekonomi }\end{array}$ & 1 & 1 & 5 & 38 & 5 & 50 \\
\hline & $\%$ & 2 & 2 & 10 & 76 & 10 & 100 \\
\hline \multirow[t]{2}{*}{4} & $\begin{array}{l}\text { Mangrove memiliki } \\
\text { manfaat penting bagi } \\
\text { lingkungan pesisir }\end{array}$ & 1 & 0 & 0 & 27 & 22 & 50 \\
\hline & $\%$ & 2 & 0 & 0 & 54 & 44 & 100 \\
\hline \multirow[t]{2}{*}{5} & $\begin{array}{l}\text { Mangrove memiliki } \\
\text { manfaat penting bagi } \\
\text { kegiatan tambak }\end{array}$ & 12 & 25 & 1 & 11 & 1 & 50 \\
\hline & $\%$ & 24 & 50 & 2 & 22 & 2 & 100 \\
\hline \multirow[t]{2}{*}{6} & $\begin{array}{l}\text { Pengelolaan hutan } \\
\text { mangrove tanggung } \\
\text { jawab bersama }\end{array}$ & 0 & 0 & 1 & 28 & 21 & 50 \\
\hline & $\%$ & 0 & 0 & 2 & 56 & 42 & 100 \\
\hline \multirow[t]{2}{*}{7} & $\begin{array}{l}\text { Penegakan hukum } \\
\text { lingkungan dinilai } \\
\text { sudah cukup memadai }\end{array}$ & 5 & 33 & 6 & 5 & 1 & 50 \\
\hline & $\%$ & 10 & 66 & 12 & 10 & 2 & 100 \\
\hline
\end{tabular}




\begin{tabular}{cccccccc}
\hline 8 & $\begin{array}{c}\text { Partisipasi masyarakat } \\
\text { dalam pelestarian } \\
\text { lingkungan meningkat }\end{array}$ & 6 & 17 & 13 & 10 & 4 & 50 \\
$\%$ & 12 & 34 & 26 & 20 & 8 & 100 \\
\hline 9 & 6 & 10 & 7 & 21 & 6 & 50 \\
\hline $\begin{array}{c}\text { Perusahaan lokal } \\
\text { berpasrtisipasi dalam } \\
\text { pelestarian lingkungan }\end{array}$ & 12 & 20 & 14 & 42 & 12 & 100 \\
\hline 10 & 0 & 2 & 5 & 40 & 3 & 50 \\
\hline $\begin{array}{c}\text { Pemda sudah } \\
\text { menjalankan tugas } \\
\text { pengelolaan } \\
\text { lingkungan dengan } \\
\text { baik }\end{array}$ & 0 & 4 & 10 & 80 & 6 & 100 \\
\hline$\%$ & & & & & & \\
\hline
\end{tabular}

Keterangan:

STS : Sangat Tidak Setuju

TS : Tidak Setuju

$\mathrm{N}$ : Netral

$\mathrm{S} \quad$ : Setuju

SS : Sangat Setuju

- Persepsi Masyarakat terhadap yaitu: kerusakan karena faktor alam

Ekosistem Hutan Mangrove

Menurut Rakhmat

(2005)

persepsi merupakan pengalaman

tentang obyek, peristiwa, ataupun

hubungan-hubungan yang diperoleh

dengan menyimpulkan informasi dan

menafsirkan pesan. Adapun persepsi

yang dimasukkan kedalam penelitian

ini yaitu :

1. Persepsi: Kerusakan wilayah pesisir karena faktor alam

Menurut Diposaptono (2001) penyebab kerusakan pesisir ada dua,
(Banjir,Tsunami,dll) dan kerusakan akibat antropogenik (Aktifitas

manusia). Berkaitan dengan kerusakan wilayah pesisir, sebesar $36 \%$ responden menyatakan sangat setuju dan 48\% responden menyatakan setuju dengan pernyataan bahwa kerusakan wilayah pesisir disebabkan karena faktor alam seperti perubahan arus, gelombang yang menyebabkan abrasi.

\section{Persepsi: Kerusakan wilayah pesisir lebih karena perbuatan manusia}

Kerusakan wilayah pesisir selain disebabkan karena faktor fisik alam 
juga dikarenakan faktor perilaku manusia. Responden sebanyak 16\% menyatakan sangat setuju dan $72 \%$ menyatakan setuju terhadap pernyataan bahwa kerusakan wilayah pesisir juga disebabkan karena pengaruh perilaku manusia

\section{Persepsi: Kerusakan hutan mangrove karena abrasi dan kepentingan ekonomi}

Menurut persepsi responden kerusakan hutan mangrove di Desa Munte pada saat ini disebabkan oleh dua faktor penting yaitu abrasi pesisir dan adanya kepentingan ekonomi seperti konversi lahan tambak yang semakin semarak. Ada $76 \%$ responden yang menyatakan setuju dan $10 \%$ responden yang menyatakan sangat setuju. Dorongan kebutuhan hidup/ekonomi mereka yang semakin meningkat telah mendorong masyarakat tidak menghiraukan lagi kelestarian lingkungan. Sebagai contoh untuk kebutuhan akan bahan bakar mereka mulai merambah hutan tanaman mangrove karena bahan bakar minyak/bahan bakar semakin mahal dan langkah. Kondisi seperti ini merupakan ancaman bagi keberlanjutan lingkungan dalam hal ini hutan mangrove.

\section{Persepsi: Mangrove memiliki manfaat penting bagi lingkungan pesisir}

Hampir sebagian responden menyatan sangat setuju yaitu sebesar 44 $\%$ dan $54 \%$ responden menyatakan setuju dengan pernyataan bahwa mangrove memiliki manfaat penting bagi lingkungan pesisir seperti manfaat menahan abrasi, menahan angin, membuat hijau pemandangan, mengurangi panas/iklim mikro, sumber kayu dan sebagainya.

\section{Persepsi: Mangrove memiliki manfaat penting bagi kegiatan tambak}

Hasil wawancara menunjukkan bahwa ada sebagian responden yang menyatakan bahwa hutan mangrove kurang bermanfaat bagi kegiatan usaha tambak. Sebanyak 50\% menyatakan tidak setuju, dan $24 \%$ menyatakan sangat tidak setuju terhadap pernyataan bahwa hutan mangrove bermanfaat bagi kegiatan usaha tambak. Menurut Lear dan Turner (1977) bahwa hutan mangrove merupakan daerah yang produktivitasnya tinggi, karena memperoleh energi berupa zat-zat makanan yang terbawa ketika pasang surut air laut. Hal inilah yang mendorong para pembenih ikan untuk 
melakukan proses budidayanya

7. Persepsi: Penegakan hukum

terutama komuditas yang bisa lingkungan dinilai sudah cukup

diusahkan pada daerah tersebut, yang memadai

salah satunya adalah budidaya ikan bandeng dan udang

\section{Persepsi: Pengelolaan hutan} mangrove tanggung jawab

\section{bersama}

Berkaitan dengan tanggung jawab pengelolaan mangrove, $56 \%$ responden menyatakan setuju dan $42 \quad \%$ menyatakan sangat setuju dengan pernyataan bahwa pengelolaan hutan mangrove merupakan tanggung jawab bersama antara pemerintah daerah, perusahaan dan masyarakat. Menurut mereka tanggung jawab pengelolaan hutan mangrove terletak pada pemerintah dalam hal ini Perum Perhutani dan Dinas instansi terkait seperti dinas lingkungan hidup, dinas perkebunan dan kehutanan serta dinas perikanan dan kelautan. Responden menyatakan bahwa tidak berhasilnya pengelolaan hutan mangrove diwilayah pesisir Desa Munte dikarenakan kegiatan penanaman mangrove umumnya lebih bersifat proyek sehingga terkesan asal-asalan dalam pelaksanaannya

8. Persepsi: Partisipasi mansyarakat
dalam pelestarian lingkungan
meningkat Adanya oknum aparat yang sering melakukan illegal loging terhadap hutan mangrove disinyalir merupakan ancaman yang tidak kalah penting bagi pengelolaan hutan mangrove. Responden sebanyak 66\% menyatakan tidak setuju; sebanyak dan $10 \%$ responden menyatakan sangat tidak setuju terhadap pernyataan bahwa penegakan hokum lingkungan dinilai sudah cukup memadai. Dengan kata lain, persepsi masyarakat terhadap isu ini berada pada rentang negatif.

Masyarakat menyadari bahwa pada saat ini partisipasi masyarakat/gotong royong ada kecenderungan mulai menurun. Hal ini ditunjukkan oleh responden sebanyak $12 \%$ menyatakan sangat tidak setuju dan responden sebanyak $34 \%$ tidak setuju terhadap pernyataan bahwa partisipasi masyarakat meningkat. Dengan kata lain, persepsi masyarakat terhadap isu ini berada pada rentang negatif. Hal ini Nampak dari semakin berkurangnya masyarakat yang ikut serta dalam setiap kegiatan gotong 
royong yang ada di lingkungannya sebanyak 80\% menyatakan setuju dan dikarenakan kesibukan masing-masing sebanyak 10\% menyatakan abstain dalam mencari nafkah, perubahan tata terhadap pernyataan bahwa pemda nilai dari masing-masing warga, juga sudah menjalankan tugasnya dengan dikarenakan adanya program yang tidak baik. Dengan kata lain, persepsi bersifat partisipatif. Masyarakat tidak masyarakat terhadap isu ini berada pada benar-benar dilibatkan secara langsung rentang positif. Responden menilai dari mulai perencanaan hingga kinerja pemerintah dalam pengelolaan pengawasannya. hutan mangrove selama ini dinilai

9. Persepsi: Perusahaan lokal cukup berhasil yang diindikasikan berpartipasi dalam pelestarian diantaranya dengan diperolehnya lingkungan penghargaan Kalpataru dari pemerintah Perusahaan swasta yang ada di pusat.

desa Munte, dinilai responden memiliki Arahan Strategi Pengelolaan kepedulian yang cukup baik dalam Mangrove turut serta melestarikan lingkungan Metode SWOT digunakan untuk termasuk hutan mangrove. Sebanyak mengidentifikasi berbagai faktor $42 \%$ responden menyatakan setuju dan internal dan eksternal secara $12 \%$ responden menyatakan sangat sistematis yang hasilnya akan setuju terhadap pernyataan bahwa digunakan untuk merumuskan perusahaan lokal berpartisipasi dalam strategi pengelolaan ekosistem upaya pelestarian lingkungan. Menurut mangrove di lokasi penelitian. Menurut Diarto (2012) sikap persepsi Rangkuti (1997), strategi trun - around masyarakat juga terbentuk karena ini dibuat untuk meminimalkan seluruh adanya upaya sosialisasi atau kelemahan yang dimiliki untuk penyuluhan yang dilakukan stakeholder memanfaatkan peluang seoptimal terkait dalam pengelolaan hutan mungkin. mangrove.

\section{Persepsi: Pemda sudah menjalankan tugas pengelolaan lingkungan dengan baik}

Responden sebanyak $6 \%$ menyatakan sangat setuju; responden
Unsur kekuatan (strength) antara lain: Sebagian kawasan hutan mangrove di desa Munte dijadikan kawasan hutan lindung, Pemerintah daerah melakukan rehabilitasi hutan 
mangrove.Unsur kelemahan (weakness) antara lain: Rendahnya tingkat pendidikan, Rendahnya tingkat ekonomi masyarakat, Lemahnya pengawasan dari pemerintah daerah.Unsur peluang (opportunity) antara lain: Pengembangan ekowisata di kawasan mangrove, Potensi usaha pembibitan mangrove, Penerapan sistem Silvofishery.Unsur ancaman (threat) antara lain: Konversi lahan, Penggunaan kayu mangrove untuk kebutuhan rumah tangga, Penebangan liar dari masyarakat luar Desa Munte, Pelibatan masyarakat harus lebih intensif.

Ada dua strategi prioritas yang dihasilkan untuk pengelolaan ekosistem mangrove di Desa Munte, yaitu (1) Meningkatkan koordinasi antar stakeholder untuk melakukan pengawasan secara bersama - sama serta (2) Menyelenggarakan pelatihan keterampilan pengelolaan mangrove. Strategi-strategi ini tentu saja harus diikuti dengan pengawasan yang intensif oleh pihak pemerintah daerah

\section{KESIMPULAN}

1. Persepsi masyarakat terhadap kriteria 1,2,3,4,6,9,dan 10 memiliki tingkat persepsi yang tinggi dengan menunjukkan bahwa nilai rata- rata skala linkert menunjukkan rentang positif. Sementara kriteria 5,7,8 menunjukkan tingkat partisipasi yang rendah dengan nilai rentang negative. Disamping itu, tingkat partisipasi masyarakat cenderung mulai menurun tercermin dari berkurangnya masyarakat yang ikut serta dalam setiap kegiatan gotong royong yang ada di lingkungannya.

2. Strategi pengelolaan berdasarkan skala yang dihasilkan untuk pengelolaan ekosistem mangrove di Desa Munte, yaitu

Menyelenggarakan pelatihanpelatihan keterampilan pengelolaan mangrove (ekowisata dan kebun bibit) untuk meningkatkan pendapatan masyarakat serta (2) Membuat regulasi untuk mengontrol pemanfaatan mangrove berbasis masyarakat dan juga pelanggaranpelanggaran pengelolaan mangrove.

\section{SARAN}

Tingkat partisipasi yang tinggi perlu dipertahankan dan ditingkatkan agar pengelolaan ekosistem mangrove dapat berkelanjutan sesuai dengan keinginan masyarakat dan diharapkan anggota kelompok masyarakat dalam pengelolaan ekosistem mangrove semakin diperkuat. 


\section{UCAPAN TERIMA KASIH}

Tulisan ini merupakan bagian dari penelitian Tesis dan penulis mengucapkan terima kasih kepada Ketua Prodi Manajemen Pesisir dan Teknologi Kelautan dan Direktur Pasca Sarjana dan Pemerintah Kabupaten Luwu Utara yang telah memberi kesempatan dan izin untuk melanjutkan pendidikan di PPS UMI Makassar.

\section{DAFTAR PUSTAKA}

Bahagia. 2008. Peran Pemerintah Daerah dan Partisipasi Masyarakat dalam Rehabilitas Hutan Mangrove Pasca Tsunami di Kecamatan Baittusalam Tahun 2008. [internet]. [diunduh pada tanggal 25 September 2015]. Tersediapada:http://repository. usu.ac.id/bitstream/123456789 /6592/1/10E00 586.pdf

Datta, Debajit, Cattopadhyay, R.N, Guha P. 2012. "Community based mangrove management: A review on status and sustainability". Journal of Environmental Management. Vol. 107, 84-95 hlm

Diarto. 2012. Partisipasi Mayarakat Dalam Pengelolaan Lingkungan Kawasan Hutan Mangrove Tugurejo Di Kota Semarang. Jurnal Ilmu Lingkungan Vol. 10 (1): 1-7.

Subandono. D. 2001. Riset teknologi pesisir: kini dan masa datang. Dalam:Rachmawati Rita,editor.
Prosiding forum teknologi konservasi dan rehabilitasi pesisir. Jakarta: Lipi Press. Hal 125.

Lear, R. and T. Turner 1977. Mangrove of Australia. University of Quennsland Press: $1-21$

Manulang, S 1999. Kesepakatan Konservasi Masyarakat dalam Pengelolaan Kawasan Konservasi. Departemen Kehutanan dan Perkebunan. Jakarta

Pangestu M.H.T. 1995. Partisipasi Masyarakat dalam Pelaksanaan Kegiatan Perhutanan Sosial (Studi Kasus: K.P.H Cianjur, Jawa Barat) ${ }^{\text {ee }}$ Tesis. Pascasarjana. Institut Pertanian Bogor. Bogor.

Rangkuti, F. 1997. Analisis SWOT Teknik Membedah Kasus Bisnis. PT. Gramedia Pustaka Utama Jakarta.

Rakhmat. 2005. Rakhmat, Jalaludin. 2005. Psikologi Komunikasi. Bandung: $\quad$ PT. Remaja Rosdakarya.

Rusila Noor, Y., M. Khazali, dan I N.N. $\quad$ Suryadiputra. 1999. Panduan Pengenalan Mangrove di Indonesia. PHKA/WIIp,Bogor.

Tambunan, R.R. Hamdani Harahap, Zulkifli Lubis. 2005. Pengelolaan Hutan Mangrove di Kabupaten Asahan. Jurnal Studi Pembangunan, 1(1): 5569. 